\title{
A INTERNET E A ENFERMAGEM: CONSTRUÇÃO DE UM SITE SOBRE ADMINISTRAÇÃO DE MEDICAMENTOS
}

\author{
Flávia Borges da Silva* \\ Silvia Helena De Bortoli Cassiani** \\ Silvia Helena Zem-Mascarenhas***
}

SILVA, F.B.da; CASSIANI, S.H.de B.; ZEM-MASCARENHAS, S.H. A internet e a enfermagem: construção de um site sobre administração de medicamentos. Rev.latino-am.enfermagem, Ribeirão Preto, v. 9, n. 1, p. 116-122, janeiro 2001.

Este estudo teve por objetivo identificar sites existentes na internet sobre o tema Administração de Medicamentos e construir e avaliar um site específico desta temática. Dos 158 sites existentes e disponíveis no banco de dados da ferramenta de busca Alta Vista, 17 destes apresentavam alguma relação com o tema tratando de farmacologia, propaganda e informações sobre remédio, tecnologias e divulgação de portarias. O restante tratava de assuntos diversos. Face a pouca disponibilidade desse recurso, foi construído o site denominado O processo de Administração de Medicamentos em foco tendo como meta divulgar investigações sobre esta temática reunidas nos seguintes tópicos: erros, tecnologia, complicações, núcleo do CNPq e equipe. A avaliação deste site foi feita por 2 analistas de sistemas, 2 técnicos de informática e 4 docentes de enfermagem mostrou que a qualidade das páginas, o tempo de resposta, os vínculos, carregamento de imagens e conteúdo como estando entre excelente e satisfatório.

UNITERMOS: internet, medicamentos, enfermagem

\section{INTRODUÇÃO}

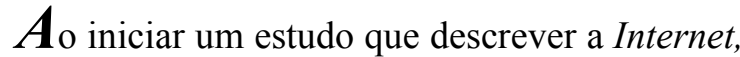
os recursos nela disponíveis e a construção de um site na enfermagem, a história do surgimento do computador é apresentada.

A construção do primeiro computador, considerado o pai dos computadores, o Harvard Mark I, ocorreu em 1944 pela International Business Machines - IBM, originário de um projeto do matemático inglês Charles Babbage, que havia apresentado, em 1833, algumas sugestões para construir uma máquina de calcular denominada de Engenho Analítico (ROCHA, 1992).

O primeiro computador digital, o ENIAC foi inaugurado em fevereiro de 1946, construído na Universidade da Pensilvânia, durante a Segunda Guerra Mundial, dentro de um programa do exército americano que procurava automatizar o cálculo de tabelas balísticas (MANDEL et al., 1997).
O ENIAC iniciou um série de gerações de computadores caracterizando a primeira geração de computadores construídos com base nas válvulas. Depois do ENIAC, surgiram o EDVAC (Eletronic Discrete Variable Computer) seguido do EDSAC (Eletronic Delay Storage Automatic Calculator) e o UNIVAC (Universal Automatic Computer) que foi o primeiro computador construído comercialmente fora das Universidades e Centros de Pesquisas (MURTA, 1999).

A segunda geração de computadores caracterizava-se pelo uso de transistores, uma novidade tecnológica para a época. Os transistores foram desenvolvidos nos Laboratórios Bell da ATT (American Telephone and Telegraph Company) em 1948 passando a ser utilizados comercialmente nos computadores em 1959 , e eram cem vezes mais rápidos e confiáveis que as válvulas. Esta geração desenvolveu-se entre os anos de 1959 até 1965 (MURTA, 1999).

A terceira geração também surgiu a partir de um novidade tecnológica criada em 1959, os circuitos

\footnotetext{
* Analista de Sistemas. Bolsista de Capatacitação Técnica da FAPESP - nível TT3 na Escola de Enfermagem de Ribeirão Preto da Universidade de São Paulo

** Enfermeira. Professor Associado do Departamento de Enfermagem Geral e Especializada da Escola de Enfermagem de Ribeirão Preto da Universidade de São Paulo. Endereço: Av. Bandeirantes, 3900 - Monte Alegre - 14040-902 - Ribeirão Preto - São Paulo - Brasil

*** Enfermeira. Professor Doutor da Universidade Federal de São Carlos
} 
integrados. Porém tratava-se de uma tecnologia cara e sua utilização nos computadores só foi viabilizada pela NASA. Esta geração se desenvolveu até 1971 (MURTA, 1999).

A partir de 1971, a classificação das gerações de computadores passou a ser divergente entre os autores e alguns até abandonaram este conceito.

O primeiro computador pessoal completo, conhecido como PC, com vídeo, teclado e CPU (Unidade de Processamento Central) foi o Alto, desenvolvido pela Xerox e comercializado em 1973. Depois dele surgiu em 1975 , na Inglaterra o primeiro computador pessoal para consumo em massa, o ALTAIR 8.800 composto de um Kit para montagem. No mesmo ano a IBM lançou o IBM 5.100 e no ano seguinte a Apple lançou o Apple2. Em 1979 a IBM lançou o IBM-PC com o primeiro sistema operacional para computadores pessoais sem a necessidade de programação, o chamado MS-DOS, pois até então era preciso que o usuário dominasse a linguagem Basic para poder controlar e manipular os dados no computador (MÜLLER, 1999).

No âmbito escolar o computador teve sua inserção na década de 50, com Skimmer propondo uma máquina para ensinar usando o conceito de instrução programada, para tanto dividia-se o material instrucional em pequenos seguimentos logicamente encadeados e denominados módulos, apresentados de forma impressa (PRICE, 1991).

Atualmente, as mudanças tecnológicas acontecem em meses e não em anos ou décadas. A cada minuto surgem novos softwares e hardwares e as transformações são rápidas e constantes. Assim, devido a variedade de produtos existentes na atualidade, cada dia mais a informática está presente no âmbito educacional e sendo utilizada como ferramenta para ajudar no aprendizado.

O computador na educação permite inúmeras possibilidades: como meio principal de ensino (sem a participação do professor), como estratégia complementar ao currículo básico (complementando o ensino feito pelo professor previamente), como arquivo de todo o currículo e atividades desenvolvidas ao qual o aluno tem acesso direto (utilizando-o de acordo com seus próprios objetivos e interesses de acordo com seu desejo de aprimoramento, obtendo maiores informações), como função avaliativa (os testes são armazenados e mediante as respostas dos alunos é feita a correção imediata de notas) e como instrumento para os alunos criarem seus próprios programas (JOLY, 1986).

A educação tem passado por constantes reformas, aperfeiçoando tecnologias na tentativa de garantir uma aprendizagem mais eficiente, numa relação pedagógica progressivamente motivadora e interativa. Hoje, sabe-se que a educação precisa caminhar junto com a informatização pois são inúmeros os recursos disponíveis por essa tecnologia (MASCARENHAS, 2000).

$\mathrm{Na}$ educação, partimos do pressuposto que o computador não substitui a figura do professor, e sim, pode ser utilizado como ferramenta de complementação, de aperfeiçoamento e de possível mudança na qualidade de ensino, propiciando condições para os estudantes exercitarem a capacidade de procurar e selecionar informação e resolver problemas (CASSIANI, 1998).

Uma das tecnologias da informática que vem auxiliando a educação tem sido a Internet, descrita a seguir.

\subsection{A Internet}

Desde o seu surgimento até os dias de hoje, a Internet vem revolucionando o modo de transmitir informações em todas as áreas, inclusive nas de educação e saúde. É uma importante ferramenta na disseminação de conhecimentos e informações, uma vez que contém um grande número de documentos com os mais variados conteúdos que podem ser consultados de qualquer parte do mundo e pelas mais diversas pessoas. Podemos definila como um grande conjunto de redes de computadores interligadas no mundo inteiro, independente do tipo de máquina utilizada para o seu acesso.

A Internet teve sua origem em 1969, nos Estados Unidos da América. Inicialmente interligava laboratórios de pesquisa e estava vinculada à área acadêmica, tendo sua liberação comercial acontecido em 1987, apresentando maior freqüência de utilização, a partir de 1992. No Brasil as universidades estão ligadas à rede de computadores desde 1989, iniciando com os serviços de correio eletrônico e transferência de arquivos.

O acesso à Internet é feito através de um provedor que pode ser acadêmico ou comercial. Dentre os vários serviços, por ela oferecidos, focalizaremos os da World Wide Web $(W W W)$ por ser o local onde os sites estão disponíveis.

A origem da Web deu-se em 1991 no laboratório CERN na Suíça. O único intuito de seu criador, TIM BERNERS-LEE, era disponibilizar documentos científicos de forma simples e fácil de acessar (SILVA, 1997).

Atualmente a Web dispõe de muitos recursos, entre eles, o hipertexto, que possibilita a interligação de textos e imagens através de palavras-chave, tornando a navegação simples e agradável e, ainda, a inserção de sons e vídeos. É conhecida como a parte multimídia da Internet.

A $W W W$ é segundo LEMAY (1996) mais informações do que você jamais poderia digerir numa vida inteira, vinculadas de várias maneiras, no universo da Internet, disponíveis para paginação sempre que desejar. 
$\mathrm{Na} W W W$ o site é disponibilizado na Internet através de um endereço eletrônico e os usuários visitam os sites através de um programa chamado browser ou navegador (VENETIANER, 1996). O site é um documento composto de tal maneira que possibilite sua exibição na $W W W($ SABBATINI \& SABBATINI, 1998).

A página principal, ou página de entrada de um site, é denominada home page e é a partir dela que os assuntos disponíveis no site estarão vinculados.

Um site pode ser utilizado para vários fins, entre eles, a comercialização de produtos, divulgação de currículos, home pages pessoais e publicação eletrônica de trabalhos científicos.

A publicação eletrônica consiste numa tecnologia de distribuição de informação em uma forma que possa ser acessada e visualizada pelo computador, utilizando, para isso, mídia digital e recursos para adquirir, armazenar e transmitir informação de um computador para outro. Como vantagens para o editor de uma publicação científica, a publicação eletrônica na Internet apresenta uma grande audiência potencial, disponibilidade universal para todas as plataformas de software $e$ hardware e baixo custo de investimento e de produção. Traz novas formas de apresentação (vídeo, áudio e interação), integração com outros sites e documentação da $W W W$. No entanto, podemos observar também desvantagens, uma delas é a falta de proteção do direito autoral devido à possibilidade de reprodução ilimitada (SABBATINI \& SABBATINI, 1998).

Uma ferramenta importante que auxilia na busca de documentos e informações sobre os mais diversos assuntos é a denominada índices ou ainda ferramentas de busca, sendo através dela podemos encontrar onde estão os documentos quando não sabemos o endereço eletrônico exato.

Atualmente, existem vários programas de busca nacionais e internacionais, entre eles, podemos citar o Cadê, o Yahoo, o Altavista, Metaminer e ainda alguns específicos para certas áreas como o Medline e Lilacs, no caso da saúde.

Sendo esta uma ferramenta poderosa, é preciso saber usá-la para ter o resultado desejado, evitando que se transforme em "tortura" e "teste de paciência". Uma das formas de evitarmos esse problema é o uso de aspas no início e no fim de uma frase para cercar o resultado; o uso do sinal menos (-) para eliminar palavra ou frase no resultado e o uso da palavra e, se o objetivo for achar palavras em uma mesma página. Escolher, ainda, palavras - chave adequadas para delimitar o assunto pretendido (SAIBA...1999).

Ao desenvolver uma webpage precisamos incluílas na lista dos sites de busca para que sua divulgação tenha um âmbito maior. A Figura 1 ilustra a home-page ou página inicial, de um dos sites de busca disponíveis na Internet.

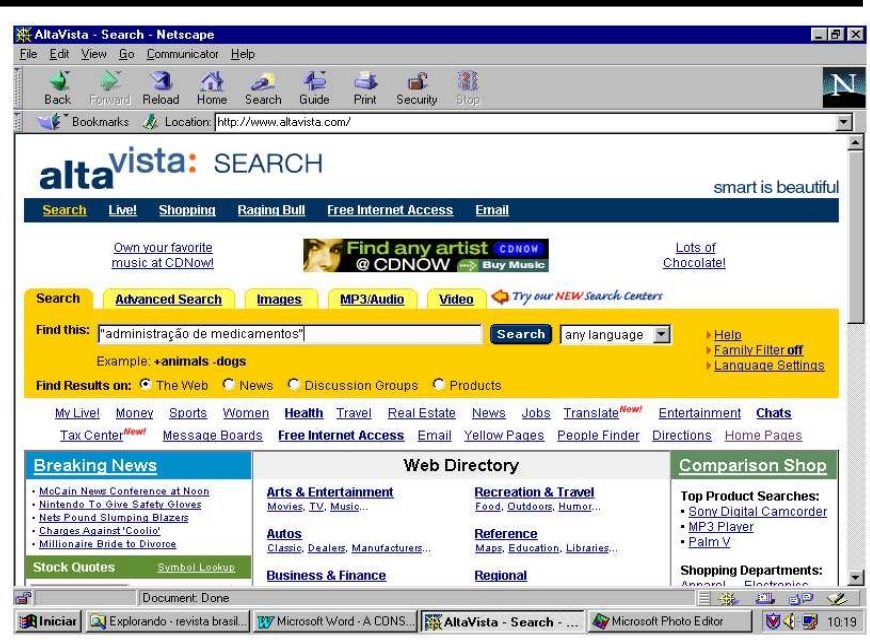

Figura 1 - Página inicial do site de busca Alta Vista

Podemos observar atualmente, cada vez mais, a penetração da Internet no ambiente acadêmico como fonte de pesquisa, divulgação e aprendizado.

Assim, segundo VENETIANER (1996) a Internet é a mais recente demonstração da infinita capacidade dos seres humanos para desenvolver tecnologias, penetrar nas profundezas do desconhecido, explorar o imaginável. É a prova cabal da busca pelo conhecimento, não tendo limites. Sendo assim, precisamos permanentemente incorporar as novas formas de busca de conhecimento que essa tecnologia nos proporciona.

Entretanto, a lentidão no estabelecimento das conexões desejadas e não saber onde e como encontrar as informações que se procuram, por exemplo, constituem obstáculos indesejáveis, porém, com certeza, as vantagens superam grandemente as desvantagens (SILVA, 1997).

Buscando reforçar a utilização da Internet na enfermagem principalmente nos aspectos educacionais e de pesquisa, este estudo foi desenvolvido a partir da construção de um site em Administração de Medicamentos. Para tanto num primeiro momento identificamos sites já existentes sobre administração de medicamentos, em seguida foi desenvolvido o site proposto e no terceiro momento o site foi avaliado.

A metodologia utilizada foi a pesquisa bibliográfica em livros, teses, periódicos e na própria Internet, além da Linguagem de programação Hyper Text Markup Language ( HTML) utilizada no desenvolvimento do site propriamente dito.

\section{RESULTADOS}

\subsection{Site existentes sobre administração de medicamentos}

O primeiro momento desse estudo teve o 
propósito de identificar site já existentes sobre a administração de medicamentos. Para tanto foi selecionado o site de busca Altavista que se constitui em um dos mais requisitados e visitados.

Ao digitar o termo "Administração de Medicamentos" no site de busca Altavista obtivemos como resultado 158 páginas relacionadas sendo que destas 17 apresentavam alguma relação com o tema como: 5 sobre farmacologia, 5 sobre propaganda informações sobre remédios, 5 sobre portarias de regulamentação de medicamento no Ministério da Saúde, 1 de tecnologia em administração de medicamentos e 1 de divulgação de informações sobre como conseguir medicamentos.

O restante 141 trataram de assuntos diversos embora relacionados à área da saúde como visto.

QUADRO 1 - Artigos relacionados ao tema "Administração de Medicamentos" na internet

\begin{tabular}{|c|c|}
\hline $\begin{array}{l}\text { Quantidade } \\
\text { de páginas }\end{array}$ & Assuntos relacionados \\
\hline 35 & $\begin{array}{l}\text { Artigos na área médica (psiquiatria, úlcera de } \\
\text { pressão, cardiologia e ginecologia) }\end{array}$ \\
\hline 34 & $\begin{array}{l}\text { Não acessavam o endereço e retornavam } \\
\text { mensagem de emo }\end{array}$ \\
\hline 23 & Fugiam ao tema saúde \\
\hline 14 & Divulgação de cursos na área da saúde \\
\hline 8 & Concursos públicos para médicos e enfermeiros \\
\hline 7 & Materiais sobre gestão hospitalar \\
\hline 5 & Farmacologia \\
\hline 5 & Propaganda e informações sobre remédios \\
\hline 5 & $\begin{array}{l}\text { Portarias de regulamentação de medicamento no } \\
\text { Ministéno da Saúde }\end{array}$ \\
\hline 4 & $\begin{array}{l}\text { Divulgavam livros, cd-rom e vídeo na área da } \\
\text { saúde }\end{array}$ \\
\hline 4 & $\begin{array}{l}\text { Endereços repetidos entre eles } 1 \text { de farmacologia, } \\
2 \text { artigos médicos e } 1 \text { de divulgação de cursos na } \\
\text { área da saúde }\end{array}$ \\
\hline 3 & Artigos na área da enfermagem \\
\hline 2 & Explicavam o que é Home Care \\
\hline 1 & Divulgavam Evento na área da saúde \\
\hline 1 & Apresentação de grupo de saúde do CNPq \\
\hline 1 & Divulgava posto médico de atendimento \\
\hline 1 & Relatónio de enfermagem \\
\hline 1 & Tecnologia em administração de medicamentos \\
\hline 1 & $\begin{array}{l}\text { Divulgação de informações sobre como conseguir } \\
\text { medicamentos }\end{array}$ \\
\hline 1 & $\begin{array}{l}\text { Manual de padronização de sistemas de } \\
\text { informação em saúde }\end{array}$ \\
\hline 1 & Produtos hospitalares \\
\hline 1 & $\begin{array}{l}\text { Destinava-se ao Grupo de Apoio a Criança com } \\
\text { Câncer }\end{array}$ \\
\hline Total $=158$ & \\
\hline
\end{tabular}

Quando inserimos as palavras-chaves "sites e administração de medicamentos" nenhum documento foi encontrado e o mesmo aconteceu quando solicitamos os termos "administração de medicamentos e erros" e "administração de medicamentos e complicações" que são assuntos relacionados ao tema investigados pelos autores.

Observamos, então, que ao solicitar um termo amplo como foi o caso de "administração de medicamentos" obtivemos um grande número de páginas como resultado entretanto com poucos realmente ligados ao tema, como já abordado. Ao delimitar-se os termos, nenhuma página era retornada.

Daí a importância de cada vez mais disponibilizarmos trabalhos, artigos e pesquisas na Internet pois esta, possui, grande parte de páginas com propaganda de produtos e apresenta deficiência de publicações científicas na área de enfoque da nossa pesquisa.

Diante da inexistência de informação específica sobre a administração de medicamentos, decidimos desenvolver um site específico sobre esse conteúdo, inclusive tendo como objetivo divulgar as investigações conduzidas pelo grupo.

\subsection{Desenvolvendo o site sobre administração de medicamentos}

\section{Conteúdo do site}

O site teve portanto, como tema central a Administração de Medicamentos reunindo conteúdo sobre pesquisas desenvolvidas por um grupo constituído por docente, alunos de graduação e pós-graduação e analistas de sistemas da Escola de Enfermagem de Ribeirão Preto - USP, autores desse estudo. Esse conteúdo considerado relevante na saúde e estando cientes da importância dos erros a ela vinculados, vimos a necessidade de divulgar os resultados dos trabalhos científicos desenvolvidos pelo grupo, na Internet, por acreditar que a ela é hoje um recurso poderoso de disseminação de informações e conhecimento. A partir da home page, é possível acessar os temas vinculados ao assunto, sendo eles: Desenvolvimento de tecnologias, Erros na Administração de Medicamentos, Complicações pós-injeções, Links vinculados ao assunto, Núcleo do CNPq e Equipe de participantes sendo que dentro destes itens podemos encontrar, ainda, a apresentação de trabalhos em congressos pelo grupo em questão.

Cada tópico possui links para os subtópicos. Assim sendo, dentro do tópico tecnologias encontraremos os sub-ítens vídeo didático, cd-rom em administração de medicamentos, teses e artigos em tecnologia educacional 
e o livro de administração de medicamentos. Nos tópicos erros e complicações estarão disponíveis fotos, bibliografias e resumos dos estudos desenvolvidos pelo grupo sobre estes temas. Dentro de links o usuário poderá ter acesso a endereços eletrônicos de sites vinculados a área da saúde. O tópico núcleo do CNPq apresenta os membros do grupo, objetivos e metas e por fim o usuário poderá acessar o ítem equipe que divulgará os participantes deste projeto.

A oportunidade de divulgar os resultados de pesquisas sobre essa temática, além de aumentar a visibilidade da equipe, encontra-se amparada na evidência do despreparo da equipe de enfermagem, o escasso conhecimento de farmacologia, fisiologia e anatomia e das complicações pós-administração de medicamentos injetáveis. Autores tem demonstrado que o despreparo dos profissionais na administração de medicamentos tem causado sérias conseqüências ao paciente, muitas vezes debilitantes, desencadeando reações indesejáveis (CARVALHO,2000).

Assim as várias formas existentes, entre elas a Internet, de disseminar conhecimentos sobre Administração de Medicamentos, deve ser exaustivamente utilizada e disponibilizada para acesso a todos. Essa foi, portanto, a principal motivação da criação desse site.

\section{Ferramentas utilizadas para o desenvolvimento}

O site foi desenvolvido buscando um formato interativo e de agradável visualização e navegação com diversificação de cores e imagens.

A linguagem de programação utilizada foi a Hyper Text Markup Language (HTML) por ser esta a mais comum para este fim.

Como suporte para a programação nesta linguagem utilizamos o programa Netscape Composer que é específico para o desenvolvimento de webpages em $H T M L$. Através deste programa os comandos HTML são inseridos automaticamente, a partir de opções selecionadas na barra de ferramentas ou nos menus de acesso.

Porém, precisamos saber da necessidade de um conhecimento prévio da linguagem HTML para termos maior liberdade de programação, uma vez que este programa é um programa fechado, ou seja, o programador fica limitado aos recursos por ele oferecidos.

Utilizamos, ainda, figuras, especialmente fotografadas, para divulgação do conteúdo de Administração de Medicamentos e ícones extraídos de sites especializados em imagens para criação de webpages.

O endereço onde esse site está disponível é: http:/ /www.eerp.usp.br/projetos/cdrom/home1.htm, cuja home page podemos visualizar a seguir na Figura 2.

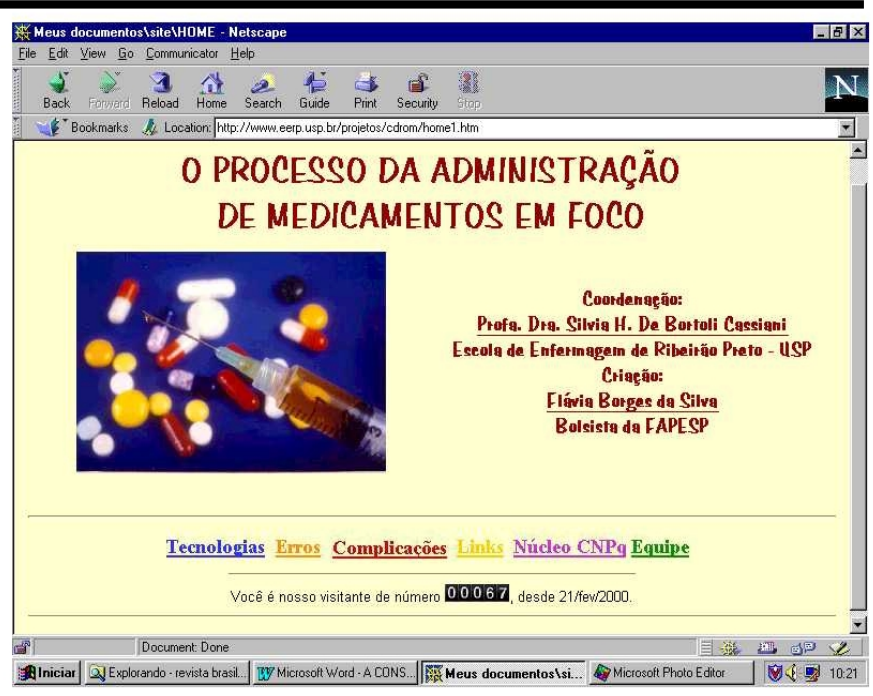

Figura 2 - Página inicial do site de administração de medicamentos

\subsection{Avaliação do site}

Uma etapa importante após o desenvolvimento de um material de tecnologia educacional sendo este um site, um CD-ROM ou um vídeo é a avaliação do produto pois esta permite saber se os objetivos e metas propostos foram alcançados.

A avaliação pode ser definida como um processo contínuo usado para determinar se os objetivos do programa foram alcançados, identificar as razões para 0 desempenho observado pelo usuário, e identificar as partes do programa que precisam ser modificadas (PRICE, 1991).

Durante a avaliação do site pudemos ter um feedback do público alvo e a partir dos resultados realizar melhorias nas suas atualizações.

Escolhemos três categorias de avaliadores para realizar os testes deste site, entre eles 2 analistas de sistemas, 2 técnicos em informática e 4 docentes de enfermagem. A escolha destas categorias ocorreu por ser esse um produto de tecnologia educacional que alia a informática a enfermagem.

O instrumento de avaliação conteve três partes e sua formulação foi baseada no modelo de PRICE (1991). A primeira solicitava do avaliador informações a respeito do equipamento e software por ele utilizado para acessar o site (processador, sistema operacional, resolução de vídeo, velocidade do provedor e navegador utilizado), isto porque estes itens podem influenciar no tempo de resposta do carregamento do site.

A Qualidade das Páginas foi avaliada na segunda parte, nesta etapa eram avaliados os seguintes itens: cor de fundo, cor das fontes, tamanho das fontes, cor dos links, imagens e aspecto visual, por fim, foi avaliado o tempo de resposta da inicialização da página principal (home page), inicialização dos vínculos 
(páginas acessadas a partir dos links) e carregamento de imagens.

Através do Quadro 2, a seguir, disponibilizamos os resultados obtidos na primeira parte avaliada Qualidade das Páginas.

Quadro 2 - Qualidade das telas

\begin{tabular}{|l|c|c|c|c|}
\hline & Insatisfat́rio & Raxoável & Satisfatório & Exrelente \\
\cline { 2 - 5 } & $\mathbf{n}^{\mathbf{0}}$ & $\mathbf{n}^{\mathbf{0}}$ & $\mathbf{n}^{\mathbf{0}}$ & $\mathbf{n}^{\mathbf{0}}$ \\
\hline Cor de fundo & - & - & 02 & 06 \\
\hline Cordas fontes & - & - & 01 & 07 \\
\hline $\begin{array}{l}\text { Tamarho da } \\
\text { fortes }\end{array}$ & - & - & 02 & 06 \\
\hline Cor dos links & - & 01 & 01 & 06 \\
\hline Imagens & - & - & 05 & 03 \\
\hline Aspecto visual & - & - & 05 & 03 \\
\hline
\end{tabular}

Pode ser percebido que a maioria dos avaliadores considerou excelente os itens cor de fundo, cor das fontes, tamanho das fontes e cor dos links e satisfatório os itens imagens e aspecto visual.

Obtivemos algumas sugestões emitas pelos avaliadores tais como: mudança de cor no item links pois a cor amarela ofusca a visão no fundo bege, inserção de imagens em formato GIF ao invés de JPG além de algumas correções de erros de digitação, que serão efetuadas nas próximas atualizações do site.

No Quadro 3, abaixo, visualizaremos os resultados das avaliações na categoria - Tempo de resposta.

\section{Quadro 3 - Tempo de resposta}

\begin{tabular}{|l|c|c|c|c|}
\hline & Insatisfat́rio & Raxoável & Satisfatónio & Exrelente \\
\cline { 2 - 5 } & $\mathbf{n}^{\mathbf{0}}$ & $\mathbf{n}^{\mathbf{0}}$ & $\mathbf{n}^{\mathbf{0}}$ & $\mathbf{n}^{\mathbf{0}}$ \\
\hline $\begin{array}{l}\text { Inicialização da } \\
\text { página princịal }\end{array}$ & - & - & 02 & 06 \\
\hline $\begin{array}{l}\text { Inicialização dos } \\
\text { vincubs (páginas } \\
\text { acessadas a partir } \\
\text { dos links) }\end{array}$ & 01 & - & 03 & 04 \\
\hline $\begin{array}{l}\text { Carregamentode } \\
\text { Imagers }\end{array}$ & - & - & 05 & 03 \\
\hline
\end{tabular}

Podemos observar que a maioria dos avaliadores considerou a inicialização da página principal e a inicialização dos vínculos e satisfatório o carregamento de imagens. Um avaliador considerou insatisfatório o item inicialização dos vínculos, porém a avaliação continha uma observação que atribuía este fato ao horário utilizado para acessar os links importantes, horário esse considerado de pico ( $17 \mathrm{hs})$ e disse que ao entrar em outro horário o tempo de resposta foi satisfatório.

\section{CONCLUSÕES}

A Internet é considerada hoje, um importante meio de comunicação tão poderosa quanto a televisão e o rádio em épocas anteriores. Ela possui uma grande quantidade de informações que podem ser utilizadas a qualquer momento e de qualquer parte do mundo.

Sua inserção no meio educacional é de suma importância, pois permite acesso rápido e barato dos mais variados tipos de assuntos inclusive divulgação de pesquisas científicas.

Os sites disponibilizados na Internet podem ser acessados por qualquer usuário de computador que possua acesso a um provedor e um browser de navegação. Seu acesso é independente do tipo de hardware e software utilizado, ou seja, pessoas com diferentes configurações de computadores (máquinas) e diferentes softwares de navegação (explorer ou netscape por exemplo) poderão acessar o mesmo conteúdo.

Observamos nesta pesquisa que a Internet ainda apresenta pouca divulgação de produção científica na Área de Administração de Medicamentos e daí a importância do desenvolvimento deste site.

Acreditamos que a inovação na criação de um site específico porém em tópico de interesse tanto de profissionais da saúde, alunos dos cursos de farmácia, medicina e enfermagem, alunos dos cursos técnicos de enfermagem, professores do ensino médio e fundamental e a população em geral, pode estimular a utilização da Internet para a divulgação técnico - científica, além de se constituir num poderoso recurso educacional.

A inserção das tecnologias educacionais ainda é uma ferramenta recente que esta se aprimorando a cada dia, e acreditamos que cada vez mais estará sendo utilizada pelos educadores uma vez que traz muitos benefícios.

\section{THE INTERNET AND THE NURSING: CONSTRUCTION OF A SITE ABOUT ADMINISTRATION OF MEDICATIONS}

This study identified existent sites in the internet about Administration of Medications and developed and evaluated a specific site of this thematic. Of the 158 existent and available sites in the database of the Alta Vista search, 17 of these presented some relationship with pharmacology, marketing and information about drugs, technologies and rules of the medication. After that a site was developed and named The process of Administration of Medications in focus which goal was to present investigations 
conducted by a group about the following topics: errors, technology, complications, study group and the team. The evaluation of this site was made by 2 analyst of systems, 2 computer science technicians and 4 nursing professors and it showed that the quality of the pages, the time of answer, the link, images and content were considered between excellent and satisfactory.

\section{INTERNET Y ENFERMERÍA: CONSTRUCCIÓN DE UN “SITE” SOBRE ADMINISTRACIÓN} DE MEDICAMENTOS

Este estudio tuvo por objetivo identificar "sites" existentes en la Internet sobre el tema Administración de medicamentos y construir y evaluar un "site" especifico de ésta temática. De los 158 "sites" exigentes y disponibles en el banco de datos de la herramienta de búsqueda Altavista, 17 de estos presentaban alguna relación con el tema tratando de farmacología, propaganda e informaciones sobre remedios, tecnologías y divulgación de disposiciones legales. El restante trataba de asuntos diversos. De cara a la poca disponibilidad de este recurso fue construido un "site" denominado El proceso de administración de medicamentos en foco, teniendo como meta divulgar investigaciones sobre ésta temática y relacionadas con los siguientes tópicos: errores, tecnologia, complicaciones, núcleo del CNPq y equipo. La evaluación de este "site” fue hecha por 2 analistas de sistemas, 2 técnicos de informática y 4 docentes de enfermería y mostró que la calidad de las páginas, el tiempo de respuesta, los vínculos, la carga de las imágenes y el contenido, se catalogan entre excelente y satisfactorio.

TÉRMINOS CLAVES: internet, medicamentos, enfermería

\section{REFERÊNCIAS BIBLIOGRÁFICAS}

\section{CASSIANI, S.H.B. Um salto para o futuro no} ensino de administração de medicamentos: desenvolvimento de um programa instrucional auxiliado pelo computador. Ribeirão Preto, 1998. 206p. Tese (Livre-Docência) - Escola de Enfermagem de Ribeirão Preto,, Universidade de São Paulo.

02. JOLY, M.C.R.A. Eficiência de um texto sobre a aquisição de conhecimento básico em computação. Tecnologia Educacional, v. 15, n. 73, p. 21-26, 1986.

03. LEMAY, L. Aprenda em 1 semana a criar Home pages na WWW com HTML. Rio de Janeiro: Editora Campus, 1996.

04. MANDEL, A.; SIMON, I.; DELYRA, J.L. Informação: computação e comunicação. Revista USP, v. 35,n. 1, p. 1-45, 1997

05. MASCARENHAS, S.H.Z. A criança e o medicamento: desenvolvimento e avaliação de um software educacinal. Ribeirão Preto, 2000. 263p. Tese (Doutorado) - Escola de Enfermagem de Ribeirão Preto, Universidade de São Paulo.
06. MÜllER, D.N. Um pouco de história do computador. [on-line]. URL: http:// www.ulbra.tche.br/ danielnm/cbc/historia/ historia.htm - Acesso em: 18/11/1999.

07. MURTA, B.H. História do computador componentes do computador. [on-line] URL: http://www.breno.com.br/historia.htm - Acesso em: 18/11/1999.

08. PRICE, R.V. Computer-aid instruction: a guide for authors. Pacific Grove, Brooks/Cole Publishing, 1991.

09. ROCHA, M.C.G. Instrução programada versus ensino por computador: um estudo comparativo de eficiência e aspectos psicoeducacionais. São Paulo, 1992. 153p. Tese (Doutorado) - Instituto de Psicologia, Universidade de São Paulo.

10. SABBATINI, M.; SABBATINI, R. Publicações médicas na Internet. Revista Informática Médica, v. 1,n. 3, p. 5, 1998.

11. SAIBA como pesquisar melhor na Internet. Folha de São Paulo, Caderno Informática, 27/10/1999.

12. SILVA, F.B. O mundo da Internet. Ribeirão Preto, 1997. Monografia - Centro de Ciências Exatas e Tecnológicas, Universidade de Ribeirão Preto.

13. VENETIANER, T. HTML - Desmistificando a linguagem da Internet. São Paulo: Makron Books, 1996. 